\title{
Comment 10.2
}

\author{
KERRY FA UL
}

South Africa (the "Rainbow Nation") is a vibrant dynamic country of 57 million people speaking at least one of the eleven official languages, spread across nine provinces. It is a country rich in natural resources with a number of well-established industries, including mining, manufacturing, and agriculture, with strong financial, transport, and communication infrastructure but with significant weaknesses in areas of labor, health, and primary education. South Africa is strongly characterized in our National Development Plan (NDP; Vision for 2030) by the three permeating challenges of unemployment, inequality, and poverty. The NDP acknowledges that science and technology, and, indeed, innovation are a means to "fundamentally alter the way people live, connect, communicate, and transact, with profound effects on economic development," with "the ability to innovate and learn by doing by investing public funding to help finance research and development in critical areas" being required. Public research institutes and universities are integral in the approach to address a number of the challenges experienced, not just as a third stream of income for the public research institute or university but also as a combination of commercialization and utilization of research results for societal benefit. South Africa experienced the same global trend in that it required a policy intervention to shift the focus at our public research institutes and universities from pure academia and teaching to knowledge transfer. In South Africa, it was the impetus of the Intellectual Property Rights from Publicly Financed Research and Development Act (IPR Act; No. 51 of 2008) that mandated the shift from "publications" to "innovations."

There is no doubt that a critical intervention that can be classified as a direct means of facilitating knowledge transfer was the legislative provision for support, including in financial terms, for the establishment of Offices of Technology Transfer. Through the "Office of Technology 
Transfer (OTT) Support Fund" the salaries of individuals within the offices are paid for by the South African government, through the National Intellectual Property Management Office, for a three-year period, giving the institution an opportunity to motivate staff for these positions to be included on their payroll thereafter. Should they not succeed, the government steps in again to ensure that capacity is not lost and provides funding for a further three-year period, but this time on a sliding scale. The funding under the OTT Support Fund also provides a ring-fenced budget for training such as licensing, technology evaluation, and later valuation, as well as marketing techniques and tips, and most recently has been expanded to now support knowledge transfer-related activities, such as IP audits, business case development, techno-economic feasibility analyses, etc. A survey conducted in 2014 and to be run every five years revealed that the South African system has just over 100 full-time equivalents and that the level of outcomes from each OTT was directly proportional to the experience of the individuals within the office.

The growing capacity at institutions has, however, been overshadowed by the "pushback" received from both academia and, in particular, industry, due to the fundamental changes the legislation brought about. For the first time, academics are now being held, to some extent, accountable for the outputs of publicly financed research and development. The impact of new legislative framework on formal knowledge transfer between academia and industry was significant as the IPR Act prescribes who owns the intellectual property. As such, industry is no longer able to instruct an institution and pay a portion of the costs and walk away with the intellectual property. The so-called default position is "s/he who creates shall own" as opposed to having the option to contractually own all IP created. This shift necessitated an effective changemanagement strategy as industry balked at instructing institutions to do research on their behalf amid the uncertainty of who would own and have access to the resulting intellectual property, and worries over whether industry would be held to "ransom," so to speak. Informal communications have revealed that the more experienced the knowledge transfer professionals, the more willing researchers are to work with them and the more productive the relationships with industry partners are. In addition, these relationships are often made or broken depending on how nimble the institution is in processing disclosures and concluding research collaboration agreements, for example. A reputation for "doing the deal" versus "making as much money as possible" also appears 
to strongly impact on the success of an OTT and the strength of the relationships built with the industry partner. This is evident in that one might put all the right direct support into the system, but if the indirect knowledge transfer channels are not operational or optimal, the ability to move the technology into the market or public space is negatively impacted.

Nine years later, the implementing office, NIPMO, continues to "demystify" the IPR Act to players across the triple helix as a critical intervention to assisting everyone to understand the clear framework that the IPR Act establishes.

In spite of these challenges, which are typically anecdotal, hence subjective, and can only be measured qualitatively, a quantitative analysis of the inputs, outputs, outcomes, and early impacts of the publicly financed research and development system in South Africa, a subset of the National System of Innovation, shows some positive upward trends. Over the period 2008 to 2014 there has been an increase in the outputs in the form of the number of disclosures received by knowledge transfer offices at institutions and an increase in the number of patent applications filed. When normalized against research and development expenditure, the increase in the outputs outstrips the growth in the inputs, namely, research and development funding. Furthermore, the conversion of these outputs into outcomes, namely, licensing arrangements or spinoff companies also increased over the period, albeit from a low base. In line with the vision of the NDP, employment is being realized with a doubling in the number of full-time equivalents employed by these SMMEs between 2008 and 2014.

As with any partnership or collaboration (or any other synonym), the core determinant of the success and longevity of the relationship depends, almost solely, on trust and a sound almost watertight contract. It is clear that over time, increases are observed in a number of formal knowledge transfer metrics, but it is the informal knowledge transfer metrics that are at the core. What is encouraging is the increase observed in the level of awareness and understanding about intellectual property and the associated rights among academia, industry, and within government. As we are enveloped by the so-called fourth industrial revolution, the role of government to fund highly risky technologies in our public research organizations will come to the fore again, providing the platform for, when they are ready, industry partners to step in and, in the words of Professor Mariana Mazzucato, "roar"! With 
the baseline now established in South Africa, time will tell whether we are indeed able to achieve critical mass in the system and thereby harness the public research system to bring innovation solutions to local problems in an emerging economy sitting at the end of the African continent. 